\title{
Putting Diversity to Work
}

\section{An Empirical Analysis of how Change Efforts Targeting Organizational Inequality Failed \\ Holck, Lotte}

Document Version

Accepted author manuscript

Published in:

Equality, Diversity and Inclusion

DOI:

10.1108/EDI-12-2015-0107

Publication date:

2016

License

Unspecified

Citation for published version (APA):

Holck, L. (2016). Putting Diversity to Work: An Empirical Analysis of how Change Efforts Targeting

Organizational Inequality Failed. Equality, Diversity and Inclusion, 35(4), 296-307. https://doi.org/10.1108/EDI12-2015-0107

Link to publication in CBS Research Portal

\section{General rights}

Copyright and moral rights for the publications made accessible in the public portal are retained by the authors and/or other copyright owners and it is a condition of accessing publications that users recognise and abide by the legal requirements associated with these rights.

\section{Take down policy}

If you believe that this document breaches copyright please contact us (research.lib@cbs.dk) providing details, and we will remove access to the work immediately and investigate your claim. 


\title{
Putting Diversity to Work: An Empirical Analysis of how Change Efforts Targeting Organizational Inequality Failed
}

\section{Lotte Holck}

\author{
Journal article (Post print version)
}

Cite: Putting Diversity to Work : An Empirical Analysis of how Change Efforts Targeting Organizational Inequality Failed. / Holck, Lotte. In: Equality, Diversity and Inclusion, Vol. 35, No. 4, 2016.

DOI: 10.1108/EDI-12-2015-0107

Uploaded to Research@CBS: September २०16 


\title{
Putting diversity to work: An empirical analysis of how change efforts targeting organizational inequality failed
}

\begin{abstract}
Purpose - The purpose of this article is to critically explore why a diversity agenda in favor of equal opportunities failed despite apparent organizational support and commitment to diversity.

Design/methodology/approach - Drawing on data from a municipal center, this study inquires into how organizational dynamics of power and hierarchy influence change efforts to alter practices of inequality. The study is positioned within critical diversity research and structured around an analysis of the researcher's fieldwork experiences.

Findings - The analysis examines into why change efforts failed despite organizational approval of a diversity agenda, open-mindedness towards change and legitimacy in regard to diversity. Paradoxically, change efforts designed to alter the status quo were, in practice, derailed and circumvented through power dynamics reproducing organizational inequality.

Research limitations/implications - A single case study in a particular type of organization constrains the generalizability but point to new directions for future research.

Practical implications - This study aims at sensitizing researchers and diversity practitioners alike to the organizational embeddedness of diversity initiatives. Accordingly, change efforts must necessarily address diversity in a situated perspective and as intersecting with key organizational power dynamics gaining impetus from macro discourses on diversity and difference.

Originality/value - Few critical diversity scholars engage with practitioners and reflect on the impact of their studies. In doing so, this paper contributes by developing diversity research, exploring the limitations and possibilities for increasing its relevance and impact.
\end{abstract}

\section{Keywords}

Critical diversity, diversity management, change, power, organizational level analysis. 


\section{Introduction}

Occasioned by increasing workforce mobility and migration, diversity in the workforce has become a prime concern for organizations. However, in an era of pervasive diversity, we face paradoxical outcomes of policies and initiatives targeting organizational diversity (Benschop et al., 2015; Ghorashi and Sabelis, 2013). While practitioners and researchers seldom question the importance of organizational diversity, how to achieve the necessary change to ensure more equal workplaces is much less obvious (Janssens and Zanoni, 2014). On the one hand, diversity management scholars promote generalized and de-politicized activities which in practice show a variation in terms of the extent to which they incorporate the promised forms of inclusiveness (cf., Dobbin et al., 2011; Jonsen et al., 2011). On the other, critical diversity scholars focus on minority experiences of discrimination and inequality in the context of historical and societal influences (cf., Gotsis and Kortezi, 2014; Van Laer and Janssens, 2011). This predominance of generalized and decontextualized diversity research has left the organizational level largely unexplored (cf., Holck et al., 2016; Zanoni et al., 2010). Consequently, there is little knowledge of why diversity change initiatives often fail and why they succeed when this occurs (cf., Ahmed, 2007; Benschop et al., 2015; Janssens and Zanoni, 2014).

To respond to this omission, the obstacles to change are explored by drawing on an interventionbased study in a municipal center, CopCorp. ${ }^{1}$ CopCorp is renowned for its diversity profile in a Danish context due to its high-skilled ethnically diverse workforce providing services for international businesses settling down in Copenhagen. Despite its reputation for diversity, CopCorp is haunted by poor employee satisfaction linked to minority employee experiences of organizational unfairness perpetuated through 'ethnicification' of task distribution and collaboration based on similarity-attraction. This article explores why change efforts targeting these two organizational practices fail despite organizational commitment, legitimacy of diversity and support for a change agenda.

The article is structured as follows: First, the study is positioned within diversity literature on the efficacy of diversity initiatives. Next, after drawing up methods applied when generating data in CopCorp, the article goes on to analyze the unfolding of two change initiatives. Finally, the article discusses its contribution and limitations together with future directions within research on diversity initiatives targeting organizational inequality.

\footnotetext{
${ }^{1}$ The name of the organization has been changed to protect its identity.
} 


\section{Diversity research}

The field of diversity management has been dominated by a social-psychological approach that stems from research on organizational behavior. This line of research assumes that negative ingroup/out-group dynamics are the product of majority individuals' biases as well as tendencies for stereotyping, to be corrected through universal human resource management (HRM) initiatives such as sensitivity training, networking to prevent minority isolation and objective rules regulating recruitment, promotion, etc. (Janssens and Zanoni, 2014; Oswick and Noon, 2014). The established research field of diversity management has been criticized for a generalized, de-contextualized and de-politicized approach, which does not capture the full range of diversity issues organizations have to deal with (Dobbin et al., 2011; Gotsis and Kortezi, 2014; Holck et al., 2016).

In contrast, critical diversity research has applied a more discursive and political lens, aimed at exposing how larger societal discourses regarding, for example, gender, sexuality or race/ethnicity obstruct diversity initiatives (cf., Oswick and Noon, 2014; Zanoni et al., 2010). Here, diversity management is deconstructed as being a normative, utilitarian and managerial rhetoric, serving in the upkeep of inequality (cf., Ahmed, 2007; Gotsis and Kortezi, 2014). Critical diversity scholars play a vital role in documenting the persistence of organizational inequality. However, only a few critical diversity studies engage with practitioners to help develop workable implications for practice (Ghorashi and Sabelis, 2013; Janssens and Zanoni, 2014; Ortlieb and Sieben, 2014).

Diversity scholars and practitioners alike underline the necessity to gain more insights into diversity practices and activities as well as how to change these since 'our current knowledge of how organizations can actually achieve power equality remains poor' (Janssens and Zanoni, 2014: 317, see also Ahmed, 2007; Zanoni et al., 2010). When listing the prevalent reasons for failure of diversity initiatives, three are highlighted: (1) Lack of accountability and responsibility structures related to the implementation of diversity initiatives (Benschop et al., 2015; Dobbin et al., 2011); (2) focus on numerical representation rather than reducing racial and gender segregating practices, which detach diversity from aspects of social justice and commitment to change (Ahmed, 2007; Ghorashi and Sabelis, 2013); and (3) failure to grasp how diversity is interlinked with power dynamics embedded in the organizational structures and routines perpetuating inequalities and normalize the privileges of the majority (Janssens and Zanoni, 2014; Ortlieb and Sieben, 2014; Oswick and Noon, 2014). In connection with this Jonsen et al. (2011) identify how most diversity research has been carried out in controlled, artificial situations or relied on archival data and surveys. 
Accordingly, research has been conducted outside the organizational flow and activities, which hampers the capacity to capture the entwinement of diversity with organizational life.

Taking as its starting point the three most common reasons for failure, this study argues that the prevalence of diversity research detached from the organizational setting results in declining practical relevance. De-contextualized abstract or generalized diversity research diminishes the ability to identify and intervene in the subtler dimensions of organizational privilege, domination and disadvantage that are routinely reconstructed in the organizational dynamics of everyday interaction (Holck et al., 2016; Zanoni et al. 2010). A situated yet critical study, on the contrary, starts with an assessment of the organizational setting and places organizational dynamics of power at the center of attention: Power is grasped as multi-dimensional in the sense that it simultaneously operates on societal, organizational and individual levels and leads to an inherent conflict of interests and scarce organizational resources (Benschop et al., 2015).

This study is based in an organizational level analysis to explore how diversity initiatives are embedded in the (unique) organizational setting with its particular configuration of power dynamics that draws on larger societal discourses on difference. This is a situated and critical approach that can help to shed light on the often ambiguous experience of diversity researchers and practitioners when trying to redress organizational inequality, and thus to gain insights into why change efforts frequently fail.

\section{Methods}

This study applies an intervention-based approach that critically engages with diversity practitioners to explore the fate of change efforts targeting inequality in a particular organizational setting. Interventions offer the possibility to experience the complications of a change process and give the study a 'participatory bent', as the participants and the researcher as a type of participant affect the research process (Gotsis and Kortezi, 2014). This study is therefore positioned in an interpretative tradition that acknowledges the co-constructed and relational nature of fieldwork and research (Ghorashi and Sabelis, 2013).

\section{Research site}

CopCorp is part of Copenhagen municipality. Its core tasks are to counsel international businesses and entrepreneurs on commercial issues as well as provide political-strategic input for the municipal 
business strategy. CopCorp successfully applies the municipal policy on diversity and equality, which predominantly focuses on recruitment strategies so that staff composition mirrors local demographics; CopCorp’s employees differ according to age, gender, ethnicity, language and cultural skills, training and work experience. Approximately one-third of the employees are highskilled with international backgrounds. An ethnically diverse workforce is a critical resource granting legitimacy to its service to international business and its contribution to the municipal business policy. Despite its reputation for diversity, CopCorp is haunted by poor employee satisfaction; almost 30\% of its employees report experiences of harassment and bullying from managers and colleagues on the basis of language, skin color and ethnicity (Employee Satisfaction Report 2014).

CopCorp was founded in 2008 with eight employees but had grown to 85 employees when fieldwork began in May 2012. The workplace culture aims at invoking a creative spirit through open-plan office space, a free-seating policy and team-based task performance characterized by few formal procedures and rules. On the one hand, employees have discretion when performing their specialized, team-based work. On the other, top management - one CEO and three section managers - has discretion in decisions on task allocation, promotion and recruitment.

CopCorp is recognized as a diversity frontrunner in a Danish context and is an example of how Danish corporations are increasingly employing a culturally heterogeneous group of employees. Once a fairly homogenous population, the demography of Denmark has significantly changed since the first Turkish 'foreign workers' arrived due to labor shortages in the 1960s (Romani et al., 2016). From the 1980s onwards, there has been an influx of immigrants and refugees from the world's hotspots and a small but growing presence of expatriates, making up $10 \%$ of the population (Statistics Denmark, 2015). As in other countries, labor market integration of ethnic minorities has been difficult with 50\% outside the labor market in Denmark (Statistics Denmark, 2015). Accordingly, diversity management in combination with active labor market policies has been adopted since the end of the last millennium as a solution to the 'diversity problem' and the tools needed to help ethnic minorities integrate into Danish workplaces (Romani et al., 2016). Regardless of diversity initiatives, ethnic minorities in Denmark are overrepresented in unemployment and in low-wage, low-skilled jobs for which they are over-qualified, and they face stronger barriers in their career progress than native-born Danes. Consequently, ethnic minorities in Denmark are generally positioned as a problematic, weak group lacking adequate competencies to fit labor market requirements (Romani et al., 2016). 


\section{Data collection}

As a former diversity consultant, the researcher already knew CopCorp and had cited their diversity work in popular folders on Danish best-practice examples of diversity management. The management's motivation for collaboration with a researcher was to redress poor employee satisfaction, especially among staff with international background through instigating change via diversity initiatives. Particular one section manager, Anna, showed strong interest in collaborating with the researcher: Nearly half of her section of 27 members had international background and this section was the primary target of the interventions that Anna planned together with the researcher to promote minority profiles and difference-including collaborative patterns. Accordingly, Anna and members from her section served as core participants: Anna was interviewed six times, shadowed on various occasions and the researcher had continuous conversations with Anna throughout the fieldwork period. Another core participant was Aya who was the target of a change initiative. Other three participants from Anna's section were interviewed several times due to their central role in planning and facilitation of interventions.

Fieldwork lasted for 24 months, but the bulk of the empirical data was collected over a nine-month period during which the researcher occupied a desk twice each week for an average of six hours. Two types of data collection techniques were applied: Open interviews and interventions.

Open semi-structured interviews were undertaken with 18 employees and managers, each of which lasted from 30 to 120 minutes. Interviewees were asked to describe their daily work patterns and the division of work, the work culture and the collaborative environment in terms of information sharing, task distribution, decision-making processes, and socializing. All interviews were recorded and transcribed. Interviewees were initially selected to ensure a variety of ethnic background and tenure; however, as the research progressed, employees showing interest in being interviewed were also included in the sample.

A summary of the sample's demographics is presented in Table 1. To protect the anonymity of the interviewees, the names are altered and their functions and background kept vague.

-- Insert Table 1 about here-- 
Interventions were applied in the form of presentations, seminars, participation in debates, informal talks and one internal report. Two events were particularly influential in this study. One was a twoday seminar and two concurrent follow-up seminars on collaborative patterns and team structures, which were held at Anna's request. The researcher facilitated the seminars, which were planned together with a committee of employees appointed by Anna. The seminars led to the formulation of a plan for rotating teamwork that was never effectuated. The second intervention was also initiated in cooperation with Anna and aimed at redressing what was seen as an unfair system of task distribution favoring majority employees with high-prestige tasks while reserving less attractive representative tasks for minority employees. These two interventions are analyzed and reflected upon in the findings section. Interventions were recorded in a fieldwork diary.

\section{Data analysis}

A thematic analysis (Silverman, 2006) was applied to interviews and interventions. This approach is productive in terms of learning about themes and patterns in qualitative data sets that emerge as important in understanding the phenomenon under scrutiny. The process of conducting thematic content analysis involves identification of prominent themes through repeated readings of the data. The transcribed interviews and field diary were coded by assigning inductive codes to segments of the data that described a particular theme within it. Coding of data facilitated interpretation by enabling a reflective, iterative process through which the content of different themes and relationships between them were explored (Essers, 2009). First, a round of basic open coding focused on the theme of how the two interventions were hampered by CopCorp's organizational setup and power dynamics, while isolating words, phrases and interaction that had been observed connected to task distribution practices, lines of authority and collaborative patterns as well as macro discourses on difference. Next step was a focused thematic coding paying particular attention to the theme of growing complex entwinement of power and micro-politics related to change efforts. These two themes are continuously dealt with in the findings section.

This particular combination of methods offered insights into important aspects of the organization of diversity, as studying change efforts and the oppositions they engender gives the opportunity to observe frequently invisible aspects of the reproduction of organizational inequalities.

\section{Empirical findings}

Change efforts to alter task distribution productive of a skew hierarchy 
Managers and employees in CopCorp take pride in emphasizing the flat and informal organizational culture with only a few rules hampering the free agency of the employees. The flat structure supposedly means that employees are equal and perform whatever tasks they are most qualified for, as reflected by the CEO: 'I do think we have equal opportunities as tasks are distributed according to professional competences. Employees do whatever they are good at - no matter if they are black or white.' However, informally there exists a job hierarchy of high-prestige political-strategic work, which predominantly consists of writing tasks and attending political meetings, and then there are representational, customer-oriented functions of consultancy and advice giving. Most employees describe the political-strategic work as high status and as the access point for advancement in the municipal hierarchy. In addition, they tend to be performed by native Danish speakers, as explained by the CEO:

Our customers are diverse and it is important to mirror this diversity among my employees: to have a variety of language competences and other cultural heritages than native-born Danes. But we also service a political system that is very 'Danish'. And some banal things like language and how to proceed in a Danish bureaucracy - well it just comes easier for ethnic Danes where Danish language skills and Danish norms just come naturally...

Even though the CEO describes task distribution as a matter of functional prioritization, this reserves high-prestige tasks for majority employees while minority employees find themselves in the representative, low-prestige job category intended to showcase the 'diversity' of the employees and their language competencies. On the one hand, preferential recruitment of employees with international backgrounds for representative tasks makes sure that they can use their unique skills as resources. On the other, this includes practices of differentiation and hierarchization with native-born Danes at the top and the international employees at the bottom. This hierarchization draws heavily on the centrality of learning the Danish language as an important step towards 'integration' in the Danish debate on diversity and difference (Romani et al., 2016). However, even though minority employees speak Danish well, they are still hampered by an assumed deficit language fluency - as reflected by the CEO. Accordingly, minority employees in CopCorp feel trapped in fixed 'ethnically' defined positions:

I am always the last link in the chain that has to do all the crappy work. I do have language challenges when it comes to writing official memos and documents in Danish. This is how I soothe myself, by recognizing this barrier to my career progress in CopCorp because there are certainly limits to the kind of work that is assigned to me.

The 'ethnified' hierarchy promotes minority feelings of injustice and partiality, but at the same time minority employees reinforce a situation of inferiority by assuming their lack of adequate Danish 
skills. Albeit not all: Aya, a newly recruited consultant with a Spanish background and a master's degree from a Danish university, aired her disagreement with managerial task distribution practices at several meetings with Eva. Eva on her part was keen to create a more inclusive workplace to counter poor employee satisfaction. Aya gave Eva an opportunity to challenge the current pattern of task distribution; due to the informality of the system, this was just a matter of distributing tasks differently than prescribed by the managerial discretionary routine. Accordingly, as a gesture of small-step change, Eva started to give strategic-political tasks to Aya.

This change in task distribution meant that Aya could not work with the colleagues that she usually collaborated with. To perform her new political-strategic tasks, Aya was dependent on the 'training' and support from the tenured 'elite' majority employees usually favored with these high-prestige tasks. They could provide her with access to information and networks as well as give feedback regarding the bureaucratic communicative style. However, none of the majority staff offered support, and their circles did not open up to Aya. She said: 'I am constantly being asked "why do you get these assignments on business policy? Why are you allowed to do this with your background?” Changing the status quo of distribution of tasks, resources and status was evidently not part of their agenda; what seemed to be at stake was not only one (minority) employee's access to professional and personal development, but the exclusive access to organizational core tasks granting a privileged position with career progress hitherto reserved for majority employees.

But Aya was also excluded among her old international colleagues. Even though most of the international staff officially criticized task distribution as unfair, they increasingly avoided Aya and silently observed her gradual decline into professional and social isolation. By stressing their valuable language and cultural skills, minority employees exclude others from the representative low-prestige work, which is then turned into a strategic position of indispensability (Ortlieb and Sieben, 2014). Paradoxically, this keeps minority employees from challenging the basic cause of inequality - the stereotypical distinction between majority and minority employees in terms of skills and competencies. In fact, they help to reinforce this stereotypical view in order preserve their own power. Feelings of social injustice further strengthen the bonds among international colleagues while expanding feelings of alienation from majority colleagues. With her new tasks, Aya was challenging this secure position of indispensability and internal solidarity based on 'us and them'.

I swim among the sharks. People keep on questioning whether 'we' - the non-Danes - have the right competencies, especially writing skills. I constantly have to prove that I am good enough. Many stand beside and wait for me to fall... I am glad I got this chance but I feel I do not belong anymore. I am in-between and have no legitimity in none of the groups. 
Anna was well aware of Aya's increasingly difficult situation. Due to the informality of the system, Anna could not force employees to collaborate with Aya. With no formal appointment or 'rites of passage', there were no official protective structures to shelter Aya. After some time, Aya felt so lost and isolated that she had a nervous breakdown. Subsequently, she took several months of sick leave. Back again, she had her old representative tasks:

Look around - all the chief consultants and managers are white Danes, and the subordinates have international backgrounds. It is irrelevant whether I have a Danish education or not. There is no will to let international employees advance in the municipal hierarchy. I would have to struggle with a million things if I was promoted - and they are 100\% linked to my background.

Despite being high-skilled, educational attainments do not allow minority employees in CopCorp to escape the negative effects of the ethnic stratification of society that undermine their chances of professional development and career progress. The general weak educational and labor market position of minorities and prevalent assumptions of linguistic deficiencies cast doubt on their professional competencies, actively disempowering minority employees. The prevailing perception is that in CopCorp - like in society at large - they do not have the same status as the majority Danes. Accordingly, high-skilled minority professionals in CopCorp are seen as and perceive themselves as stereotypic 'low-skilled' immigrants and not as well-educated professionals, which preserves organizational patterns of inequality.

\section{Change efforts to alter collaborative patterns of similarity-attraction}

Officially, collaboration between dissimilar employees is held to further creativity, innovation and information sharing among the employees and managers in CopCorp. This is to ensure satisfactory service to international businesses and strategic input to Copenhagen's international business strategy, which are the core tasks in CopCorp. As a team-based organization, well-functioning collaboration is vital to high-quality task performance. For the employees, collaboration is furthermore important to career prospects and professional development: Tasks are apparently distributed depending on the qualification and experiences of the team members. If you collaborate with experienced co-workers with long tenure that are tightly connected to the municipal hierarchy, then high-prestige tasks flow your way. In addition, team members are employees' primary contacts in the organization, sheltering them from social isolation and serving as back-up and support in periods of work overload and stress. Hence team members are vital to both professional and social life in CopCorp. 
The official intention is that employees work together ad hoc, changing teams where composition of knowledge and competencies of the team members are matched with the task(s) at hand. In practice, employees described how they all work in fixed groups displaying similar professional, social and cultural/language related features:

We are incredibly similar and nothing separates us. We have exactly the same background, education and work experience. We work together as a team every day. We know exactly what the other team members will answer and exactly what we will get from them.

A sense of guilt and shame accompanies collaborative patterns, especially as many of the employees work professionally with diversity-related issues. Collaboration patterns based on similarity-attraction is a recurrent theme among Anna's section members:

There is a tendency to distinguish between the Danes and the 'foreigners'. This is very unfortunate not only socially but also professionally. People tend to work together with people with the same ethnical background.

To redress these segregating collaborative practices, Anna initiated a series of seminars. The purpose of the seminars was to collectively reflect on the existing collaboration practices and perceptions about the 'other' (out-) groups in the section, and to identify ways of collaborating to ensure cross-cultural and cross-professional exchange. Anna wanted to motivate employees to collaborate differently of their own free will, true to the decentralized, democratic spirit of a teambased organization. As a gesture of micro-politics to mobilize a strong alliance to carry through her change agenda, Anna appointed a planning committee consisting of eight employees whom she believed represented the different 'groupings' and strong individuals with both majority and minority backgrounds.

To illustrate the lack of diversity in the existing teams and the prospect of more mixed teams - in regards to variation in professional training, tenure and language/cultural skills - one of the seminar activities was an exercise to map a competence chart of current and future more mixed teams. To carry through this exercise, the section members were divided into groups by the committee members based on who usually worked together. This created widespread outcry and resentment - a reaction that perplexed the committee members:

It is an odd, but noteworthy, general response to the group exercise: 'I do not want to be part of that group... I will not be identified with that group. It is a little less significant than the others'. It is incredible that people react so strongly even though they all recognize the groups. I guess there is a desire to signal membership of a particular league. 
Subsequently, the committee members reflected on how - by making the implicit explicit employees feel 'boxed in' and locked into certain employee categories and group membership designating a position in the intern hierarchy. The seminars gave employees the opportunity to talk about how collaborative patterns both grant and block access to privilege, knowledge and network in CopCorp. These collective reflections and scenarios of more open collaboration patterns based on sharing and reciprocal development created a strong consensus for altered collaborative patterns manifesting in a collectively formulated plan for rotating teamwork that all section members agreed to implement.

Throughout the phase of planning and carrying through the seminars, Anna enjoyed the support of the committee and section members as well as the managerial level in CopCorp, eager to boost the diversity potential and image of the organization. However, when initiating the implementation of the plan for rotating collaboration, Anna witnessed the decline of her status and support in her section. This was not an open resistance but a silent rejection of carrying out the planned change: In particular, majority members characterized by long tenure kept on collaborating with their similar peers, disregarding the plan for rotating teams. Knowing the 'ropes' and procedures of the municipal bureaucracy and having privileged access to high-prestige political-strategic tasks, their resistance to opening up their circle to more peripheral members was detrimental to the implementation of rotating teamwork. With no formal rules or procedures for team formation in place but the collectively agreed plan for teamwork, Anna could only motivate with words and through the social sanctions of publicly reprimanding the lack of effectuation. This made Anna an increasingly unpopular figure in her section, and tenured members of her team started to bypass her by going directly to the CEO, isolating her as a manager. Having vested all her authority in carrying out the plan for rotating teamwork, she lost her power as well as her confidence as a manager:

The plan for rotating teams was written down and ready to implement: I had appointed coordinators responsible for effectuating the rotating principle so the teams at any time would reflect a variety of competencies. But nobody supports my decisions and I can’t take responsibility as a leader anymore.

This situation left her with no other option than to opt out of the organization, leaving many of her section members highly frustrated by the whole process:

It is extremely demotivating. Everything we have done in these collaborative seminars, our efforts to find some common values and the areas in which we excel... this is all gone. There is no team spirit left and people go in opposite directions. This is demoralizing for all of us. It did make a lot of fuss, but it just crumbled to pieces afterwards. 
Even with apparent structural support and accountability, as CopCorp had in Anna, instigating diversity changes in a team-based, informal organization can become an ephemeral and volatile endeavor as their success depends on employees continuing to act upon them. In particular, the 'blessing' of tenured majority employees is pivotal to carrying through change. Their silent resistance demonstrates CopCorp as an organization affected by micro-politics where majority employees exert their influence unrestrained through networks and silent lobbying in pursuit of individual opportunities. The fluid organizational lines of authority made it possible for tenured majority members to erode Anna's authority through avoidance and derailing her decisions by keeping up their collaborative routines. The opacity of the circuit of authority resulted in loose couplings between official intention and practice, rendering diversity initiatives 'toothless' as they are easily hijacked and circumvented by practices perpetuating inequality.

\section{Concluding discussion}

Studying change efforts in CopCorp uncovers how diversity initiatives are embedded in the organizational setting and draws on societal discourses on difference. These findings emphasize the benefits of an organizational-level study in contrast to current diversity research predominantly grounded in de-contextualized, generalized and abstract studies (Jonsen et al., 2011; Ghorashi and Sabelis, 2013; Gotsis and Kortezi, 2014; Zanoni et al., 2010). This situated study demonstrates how the prevalence of generalized and de-contextualized research fail to assess and hence redress the often tacit, organizational 'underbelly' of power battles related to privilege, disadvantage and resistance. As a consequence, challenging organizational practices of inequality must address these power relations, as argued by critical scholars, albeit in their localized setting; in CopCorp, empowerment of hitherto disadvantaged minority employees involved a showdown with organizational collaborative and task distributive practices that perpetuate an unsound ethnical hierarchy.

However, providing an 'adequate' diagnosis does not necessarily translate into a successful cure: In CopCorp diversity initiatives helped to articulate minority frustrations particularly - at least for a while. But changing conversations need not translate into changing practices in favor of equal opportunities (Holck et al., 2016; Ortlieb and Sieben, 2014; Oswick and Noon, 2014). Change efforts in CopCorp demonstrate how changing patterns of inequality involves the whole organization and the acceptance of loss of majority privilege for the benefit of the community. However, the situation of minority employees is more ambiguous. On the one hand, they work 
within an organizational setting that reflects and sustains majority privilege. On the other, they benefit from a favorable position which arises from their specific skills for dealing with international customers and representing the company. This situation is complicated by the ambiguity of ethnicity as a skill in itself and as inherently deficient as it draws on societal discourses that rest on a binary of 'real Danes' and 'immigrants', marginalizing the entire group of minority employees. International employees are simultaneously valued as contributing to organizational agendas of increased internationalization and constructed as problematic others lacking the required language competence and hence difficult to work with. Despite widespread feelings of unfairness attached to 'ethnified' task distribution, few minority employees therefore actively support a change of task distribution, granting them a privileged access to but also pigeonholing them in representative, low-prestige tasks. Notably, employees from both the majority and minorities gain from this paradoxical minority position of privilege-disadvantage, which in turn perpetuates the status quo. Imposing change efforts to alter unfair practices of task distribution can thus amplify segregating practices, widening the social and professional gap between minority and majority to the detriment of cross-cultural collaboration in a vicious circle, like in CopCorp.

The contribution of this article is to highlight how research on change efforts must focus on their situatedness; how change processes are unfolding and negotiated in the organizational context; and the relationality of the 'change agents' when tactically navigating the multi-dimensionality of organizational power while exposing structures of privilege and disadvantage. Future critical diversity research needs to engage more actively with practitioners to understand both diversity managers' and researchers' agency in organizational change processes. This involves ethical aspects linked to problems of difficult and unpredictable situations that arise from intervening, which would help to further knowledge about what actually happens when trying to ignite change. The organizational impact of participative engagement needs to be critically assessed together with the ethical organizational implications of intervening in diversity processes.

\section{References}

Ahmed, S. (2007), “The language of diversity”, Ethnic and racial studies, Vol. 30 No. 2, pp. 235256. 
Benschop, Y., Holgerson, C., van den Brink, M. and Wahl, A. (2015), Future challenges for practices of diversity management in organizations, in Bendl, R. et al (eds.) Oxford Handbook of Diversity in Organization. Oxford: Oxford University Press.

Dobbin, F., Soohan, K. and Kalev, A. (2011), “You Can’t Always Get What You Need: Organizational Determinants of Diversity Programs”, American Sociological Review, Vol. 76 No. 3, pp. 386-411.

Essers, C. (2009), "Reflections on the Narrative Approach: Dilemmas of Power, Emotions and Social Location While Constructing Life-Stories”, Organization, Vol. 16 No. 2, pp. 163-81.

Ghorashi, H. and Sabelis, I. (2013), “Juggling difference and Sameness: Rethinking strategies for diversity in organizations”, Scandinavian Journal of Management, Vol. 29 No. 1, pp. 78-86

Gotsis, G. and Kortezi, C. (2014), Critical Studies in Diversity Management Literature: A Review and Synthesis, London, Springer.

Holck, L., Muhr, S. and Villeseche, F. (2016), “Identity, diversity and diversity management: On theoretical connections, assumptions and implications for practice”, Equality, Diversity and Integration: An International Journal. Vol. 35 Iss: 1, pp.

Janssens, M., and Zanoni, P. (2014), “Alternative diversity management: Organizational practices fostering ethnic equality at work”, Scandinavian Journal of Management, Vol. 30, pp. 317-331.

Jonsen, K., Maznevki, M.L. and Schneider, S.C. (2011), "Special review article: Diversity and its not so diverse literature: An international perspective”, International Journal of Cross Cultural Management, Vol. 11 no. 1, pp. 35-62.

Ortlieb, R., and Sieben, B. (2014), "The making of inclusion as structuration: empirical evidence of a multinational company”, Equality, Diversity and Inclusion: An International Journal, Vol. 33 No. 3, pp. 235-248.

Oswick, C., and Noon, M. (2014), "Discourses of diversity, equality and inclusion: trenchant formulations or transient fashions?”, British Journal of Management, Vol. 25 No. 1, pp. 23-39.

Romani, L. Holck, L. Holgersson, C and Muhr, S.L (Forthcoming 2016), "Diversity Management and the Scandinavian Model: Illustrations from Denmark and Sweden”, in J.F Chanlat and M. 
Özbilgin (Eds.) Management \& Diversity: Main constatations in different countries. London: Emerald.

Silverman, D. (2006), Interpreting Qualitative Data, London: SAGE.

Van Laer, K. \& Janssens, M. (2011), “Ethnic minority professionals' experience with subtle discrimination in the workplace”, Human Relations, 64(9): 1203-1227.

Zanoni, P., Janssens, M., Benschop, Y. and Nkomo, S. (2010) 'Unpacking diversity, grasping inequality. Rethinking difference through critical perspectives’, Organization, 17(1): 9-29. 